\title{
Analysis of the notch effect of welded joint and of grinding effect
}

\author{
V. $\operatorname{Kliman}^{1 *}$, V. Chmelko ${ }^{2}$, M. Margetin ${ }^{2}$ \\ ${ }^{1}$ Institute of Materials and Machine Mechanics, Slovak Academy of Sciences, \\ Račianska 75, 83102 Bratislava 3, Slovak Republic \\ ${ }^{2}$ Slovak University of Technology in Bratislava, Faculty of Mechanical Engineering, \\ Institute of Applied Mechanics and Mechatronics, Námestie slobody 17, 81231 Bratislava, Slovak Republic
}

Received 26 May 2014, received in revised form 2 October 2014, accepted 22 July 2015

\begin{abstract}
This study deals with the experimental investigation of the notch effect of steel welded joints. For the selected type of weld, experiments were carried on welded low carbon steel specimens prepared by MIG technology to separate the influence of geometrical and technological factors on fatigue life and to define dependence of total, technological and geometrical notch coefficients of the welded joints on number of cycles to failure. The effect of notch and removing the geometrical concentrator by weld grinding is analyzed from the probability viewpoint, both in low and high cycle domains. The results show that the weld grinding is not always positive on fatigue life, and probabilistic approach is necessary to define its optimal use. Fractography analysis shows that the fatigue crack is initiated exclusively in the weld toe and within the inner weld defects at the high cycle domain and high-stress amplitude loading, respectively.
\end{abstract}

K e y w o r d s: welded joint, weld notch coefficient, weld grinding effect, fatigue life, probabilistic analysis, random loading

\section{Introduction}

Due to the notch effect, the welded joint is a part of the structure where a fatigue crack can often be expected. Reduction of the notch effect and assessment of the fatigue resistance of the welded joint is, therefore, one of the key tasks for ensuring the reliable operation of a mechanical structure. The assessment principle consists of comparing the local stress in the weld with a standardized $S$ - $N$ curve for a given type of a welded joint. A survey of approaches to the fatigue life estimation of welded joints based on various concepts (nominal stress, hot spot stress, notch stress, fracture mechanics) can be found in works [1-4] and the standards of the design of welded structures, as well as International Institute of Welding (IIW) recommendations, are in works [5] and [6].

The notch effect itself, represented by the notch coefficient $\beta$ of the welded joint is a function of many factors (the way the weld is made, heat treatment, the occurrence of bubbles, residual stresses, weld geometry, etc.), and their combined impact can be different for each of the welds made. Moreover, it can be distinctly different in low and high cycle domains. This results in a scattering of experimental points along the fatigue life curve of the welded joint and subsequently in the necessity to interpret both the notch effect and fatigue life of the welded joint in a probabilistic way [7]. Information on the notch effect of the weld, necessary for fatigue life estimation, can be obtained experimentally or by using theoretical and numerical approaches. The theoretical approaches, however, are based on many simplifications and idealizations that can underestimate or overestimate the influence of some factors. Therefore, the most suitable ways of obtaining information on the notch effect of a certain type of welded joint are experimental methods.

This study deals with the experimental investigation of the influence of the notch effect on fatigue strength of butt-welded joints in structural steel. The notch effect is analyzed from the probability viewpoint, both in low and high cycle domains. The effect of removing the geometrical stress concentrator by weld grinding, which is a post welded operation frequently used to lower the notch effect, is also investigated.

\footnotetext{
*Corresponding author: tel./fax: +421 2 59309417; e-mail address: ummsklim@savba.sk
} 
Table 1. Chemical composition and mechanical properties of base material, Steel 11523 (S355J2C+C)

\begin{tabular}{ccccccccccc}
\hline $\begin{array}{c}R p_{0.2} \\
(\mathrm{MPa})\end{array}$ & $\begin{array}{c}R m \\
(\mathrm{MPa})\end{array}$ & $\begin{array}{c}A 5 \\
(\%)\end{array}$ & $\begin{array}{c}\mathrm{C} \\
(\%)\end{array}$ & $\begin{array}{c}\mathrm{P} \\
(\%)\end{array}$ & $\begin{array}{c}\mathrm{S} \\
(\%)\end{array}$ & $\begin{array}{c}\mathrm{Mn} \\
(\%)\end{array}$ & $\begin{array}{c}\mathrm{Si} \\
(\%)\end{array}$ & $\begin{array}{c}\mathrm{Cu} \\
(\%)\end{array}$ & $\begin{array}{c}\mathrm{Al} \\
(\%)\end{array}$ & $\begin{array}{c}\mathrm{CEV} \\
(\%)\end{array}$ \\
\hline 612 & 644 & 19 & 0.19 & 0.018 & 0.017 & 1.32 & 0.4 & 0.06 & 0.035 & 0.44 \\
\hline
\end{tabular}

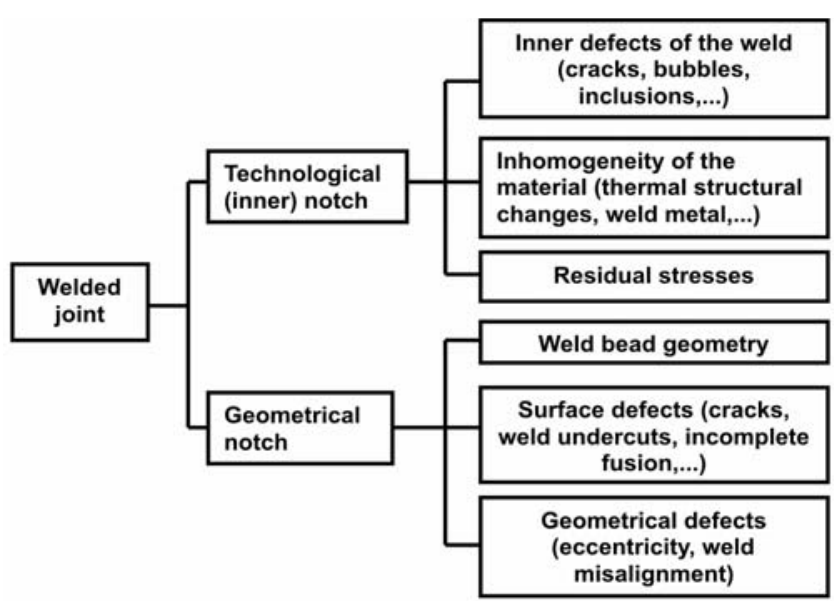

Fig. 1. Factors representing weld notch effect.

\section{Experimental procedure}

The aim of the experiment is:

a) for a selected type of welded joint (Fig. 4), to obtain the fatigue life curves of the basic material, the welded joint and the welded joint with the ground (smoothed) weld,

b) by their comparison, to judge the real notch effect of the weld and the possibilities of its reduction by the grinding operation.

For this purpose, all factors influencing the fatigue life of the welded joint, and which occur in every weld, are divided into two groups:

- factors representing the technological (inner) notch,

- factors representing the geometrical notch.

The technological notch is represented by factors arising as a consequence of the welding technique itself. These are all weld defects under the surface (cracks, porosity, inclusions, bubbles, etc.), structural changes in the material, and residual stresses arising during the welding process. The geometrical notch is represented by factors occurring on the weld surface. These are mainly weld bead geometry and weld defects observable on the visible surface such as cracks, rewelding of the root, root penetrations, and weld undercuts. This division is schematically presented in Fig. 1, and individual factors are discussed in detail in the work [8].

The division in Fig. 1 also reflects the possibilities for improving the fatigue properties of the welded

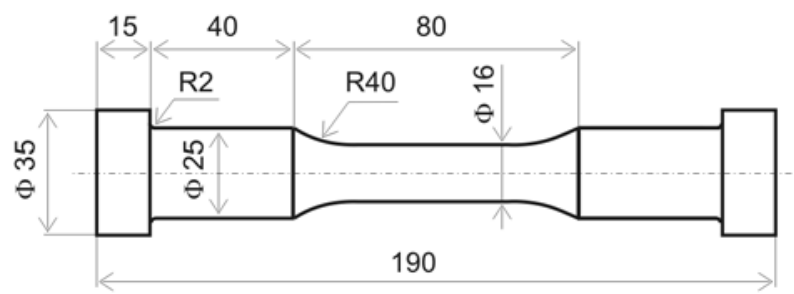

Fig. 2. Test specimen for basic material - a smooth unwelded specimen.

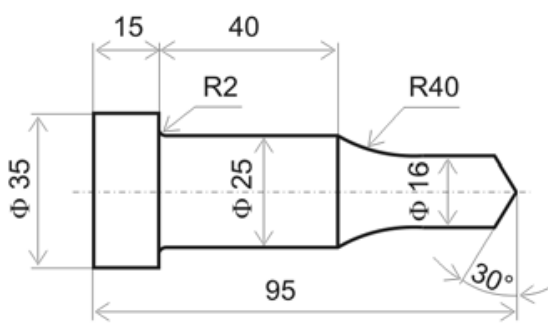

Fig. 3. Specimen blank for the production of welded test specimen.

joint. The effect of the geometrical notch can be reduced using the post-welded operations such as weld regrinding, shot peening and weld toe remelting using TIG technology. The influence of the technological notch can be reduced by the optimization of welding technology (modification of welding parameters, changes in the geometry of the semi-product and welding techniques).

By regrinding the weld, it is possible to separate experimentally the influence of technological and geometrical notch, and in this way to quantify their share in the total notch effect of the welded joint.

\subsection{Test specimen and experimental results}

The fatigue life curves were obtained for three types of test specimens:

A - a smooth unwelded specimen (Fig. 2), made of the basic material 11523 (S355J2C+C). The chemical composition and material characteristics given by the producer are in Table 1. Test specimens were made by turning and finished by grinding.

$\mathbf{B}-a$ welded specimen (containing both geometrical and technological notches). The test specimen was made by welding of two parts (Fig. 3) in a special 


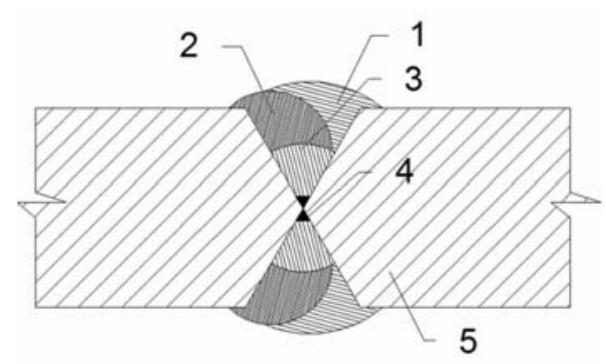

Fig. 4. The layout of welded joint. 1, 2, 3- weld beads made by MIG technology; 4 - core of weld made by TIG technology; 5 - basic material.

jig to secure the axial alignment. The surface of both parts was ground prior to welding as well. In the first step, both parts were joined in the weld root using TIG technology (welding with a nonconsumable tungsten electrode) and the rest of the weld was completed by manual welding using MIG technology (argon $+\mathrm{CO}_{2}$ shielded welding with a consumable electrode) in three layers (Fig. 4). The filler material and its composition are in Table 2.

$\mathbf{C}-a$ welded and subsequently machined specimen (with removed geometrical notch). It was made by the same procedure as specimen B. However, after welding, the turning and grinding of the surface followed in such a way that the geometry of the final specimen was identical with specimen A (Fig. 2).

Individual sets of specimens $\mathbf{A}, \mathbf{B}$, and $\mathbf{C}$ were loaded by a harmonic cycle with $R=-1$, at the loading mode $\sigma_{\mathrm{a}}=$ const., in a servohydraulic test system EDYZ-6 produced by the INOVA company. The results of fatigue tests for individual test series are in Table 3, and in the form of fatigue life curves in Fig. 5.

Fatigue life curves $\mathbf{A}, \mathbf{B}$ and $\mathbf{C}$, in the form of Basquin's [9] equation are

$$
\sigma_{\mathrm{a}}=\sigma_{\mathrm{f}}^{\prime}\left(2 N_{\mathrm{f}}\right)^{b},
$$

where $\sigma_{\mathrm{a}}$ is the stress amplitude, $N_{\mathrm{f}}$ is the number of cycles to fatigue failure, $\sigma_{\mathrm{f}}^{\prime}$ is the fatigue strength coefficient, $b$ is the fatigue strength exponent. The fatigue life curves are determined for some cycles $\left(N_{\mathrm{f}}\right)$ up to the so-called "technical initiation of fatigue crack" ( $0.5-1 \mathrm{~mm})$.

The number of cycles prior to the initiation of the fatigue crack was determined on the basis of continuous measurement of the deformation response to

Ta b l e 2. Chemical composition and mechanical properties of welding wire, CARBOFIL 1A GOLD, producer OERLIKON

\begin{tabular}{cccccccc}
\hline $\begin{array}{c}R p_{0.2} \\
(\mathrm{MPa})\end{array}$ & $\begin{array}{c}R m \\
(\mathrm{MPa})\end{array}$ & $\begin{array}{c}A 5 \\
(\%)\end{array}$ & $\begin{array}{c}\mathrm{C} \\
(\%)\end{array}$ & $\begin{array}{c}\mathrm{P} \\
(\%)\end{array}$ & $\begin{array}{c}\mathrm{S} \\
(\%)\end{array}$ & $\begin{array}{c}\mathrm{Mn} \\
(\%)\end{array}$ & $\begin{array}{c}\mathrm{Si} \\
(\%)\end{array}$ \\
\hline 460 & $550-630$ & 24 & 0.06 & 0.02 & 0.03 & 1.7 & 0.9 \\
\hline
\end{tabular}

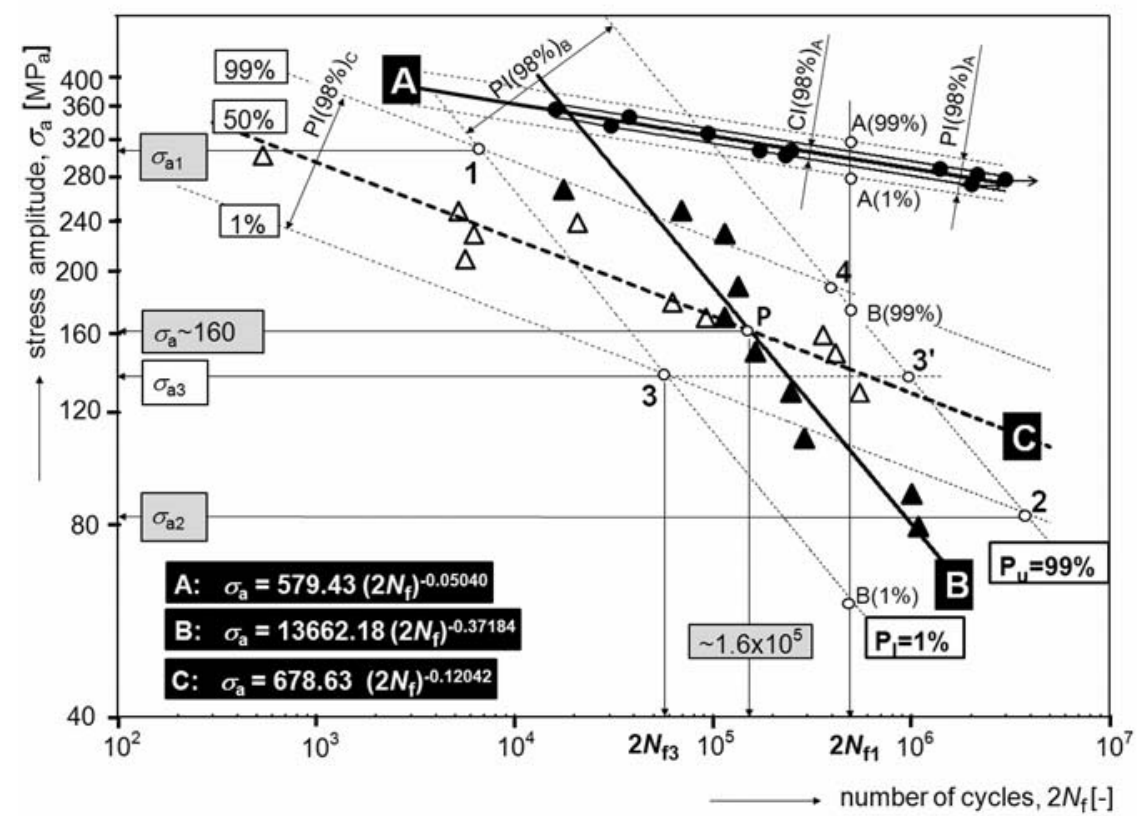

Fig. 5. Fatigue life curves. A - basic material; B - welded joint; C - ground welded joint; $P I(98 \%)-98 \%$ prediction interval; $C I(98 \%)-98 \%$ confidence interval; $P_{1}$ - lower tolerance limit; $P_{\mathrm{u}}-$ upper tolerance limit. 
Ta b l e 3. Fatigue life test results. $\mathbf{A}$ - basic material; $\mathbf{B}$ - welded joint; $\mathbf{C}-$ ground welded joint

\begin{tabular}{|c|c|c|c|c|c|}
\hline \multicolumn{2}{|c|}{$\mathbf{A}$} & \multicolumn{2}{|c|}{ B } & \multicolumn{2}{|c|}{ C } \\
\hline$\sigma_{\mathrm{a}}(\mathrm{MPa})$ & $N_{\mathrm{f}}(-)$ & $\sigma_{\mathrm{a}}(\mathrm{MPa})$ & $N_{\mathrm{f}}(-)$ & $\sigma_{\mathrm{a}}(\mathrm{MPa})$ & $N_{\mathrm{f}}(-)$ \\
\hline 358.10 & 7991 & 268.57 & 8719 & 303.39 & 266 \\
\hline 348.15 & 18738 & 248.68 & 34437 & 248.68 & 2584 \\
\hline 338.20 & 15328 & 228.79 & 56690 & 238.73 & 10317 \\
\hline 328.26 & 47021 & 189.00 & 66856 & 228.79 & 3084 \\
\hline 308.36 & 85523 & 169.10 & 56948 & 208.89 & 2791 \\
\hline 308.36 & 123746 & 149.21 & 81467 & 179.05 & 31033 \\
\hline 303.39 & 116000 & 129.31 & 123343 & 169.10 & 45854 \\
\hline 288.47 & 690864 & 109.42 & 144058 & 159.15 & 179000 \\
\hline 283.49 & $2154338^{*}$ & 89.52 & 498399 & 149.21 & 205922 \\
\hline 278.52 & 1481861 & 79.58 & 539540 & 129.31 & 273357 \\
\hline 173.55 & $2000000^{*}$ & - & - & - & - \\
\hline
\end{tabular}

*stopped test

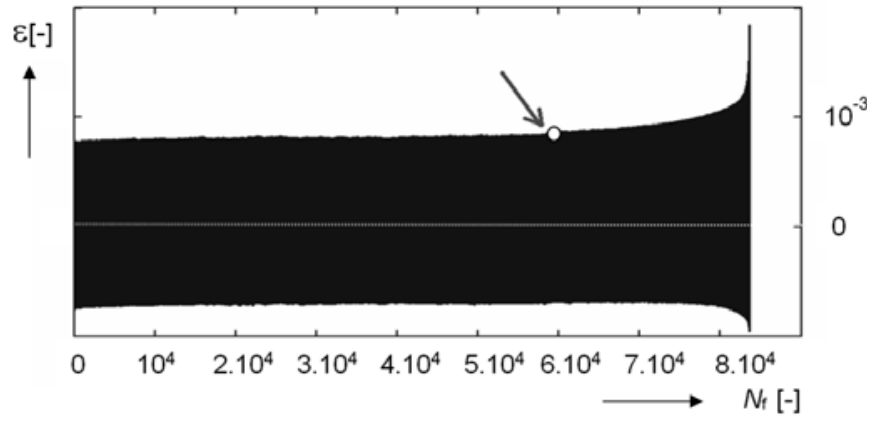

Fig. 6. Determination of some cycles to "technical fatigue crack initiation".

the loading regime of the test specimen $\sigma_{\mathrm{a}}=$ const. (Fig. 6).

\section{Results analysis and discussion}

The fatigue life curves (FLC) for individual specimen sets $(\mathbf{A}, \mathbf{B}, \mathbf{C})$, together with the tolerance limits, are depicted in Fig. 5. The width of the tolerance band (a band in which the expected result can be found with the desired probability $P \%$ ), reflects the real magnitude of the scatter of experimental points around the FLC. The magnitude of the scatter is a significant parameter for judging the notch effect of the weld and the weld grinding effect, and depends on welding technology, the weld quality, the kind of post-welded treatment, etc. We distinguish a confidence interval $C I$ (the band in which the whole regression line can be expected with the desired probability) and a prediction interval PI (the band in which an individual experimental result can be expected with the desired probabil- ity). For the evaluation of the influence of the weld notch effect on the fatigue life, it is necessary to consider the scatter of experimental points, i.e. the $P I$, since each experimental point around the curves $\mathbf{B}$ and $\mathbf{C}$ can in practice represent an individual weld joint.

Fatigue life curves $\mathbf{A}, \mathbf{B}, \mathbf{C}$, in the form of Eq. (1), were obtained by statistical processing of the experimental results in Table 3. The tolerance limits (lower limit $P_{1}$ for the probability of occurrence $1 \%$, upper tolerance limit $P_{\mathrm{u}}$ for $99 \%$ ) can be obtained in the analytical form on the base of the method according to [10]. This method is based on the supposition of a log-normal distribution of the number of cycles to failure and shifting the regression curve to the desired value of probability of occurrence. A detailed application of this method to the FLC in the form of Eq. (1) can be found in [7]. However, a more precise analytical expression can be obtained by regression (using Eq. (1)) over the points of the tolerance limit for the tested life section. In our case, we used this method and the fatigue life curves $\mathbf{A}, \mathbf{B}$ and C are compared over the domain $2 N_{\mathrm{f}} \approx\left(2 \times 10^{4}\right.$ $\left.2 \times 10^{6}\right)$. In order to consider the whole scatter band of experimental points along the regression lines in the analysis of the notch effect of the weld, we chose the tolerance band with the probability of occurrence $P=98 \%$. This means that under a loading with amplitude of stress $\sigma_{\text {a }}$ (Fig. 5), the $98 \%$ of experimental results can be expected between the lower $\left(P_{\mathrm{I}}\right)$ and upper $\left(P_{\mathrm{u}}\right)$ tolerance limit (between the points 3 and 3 ' for the curve $\mathbf{B}$, when $\sigma_{\mathrm{a}}=$ $\left.\sigma_{\mathrm{a} 3}\right)$.

\subsection{The notch effect of the weld}

The notch effect of the weld, characterized by the notch coefficient $\beta$, can be expressed in the time do- 


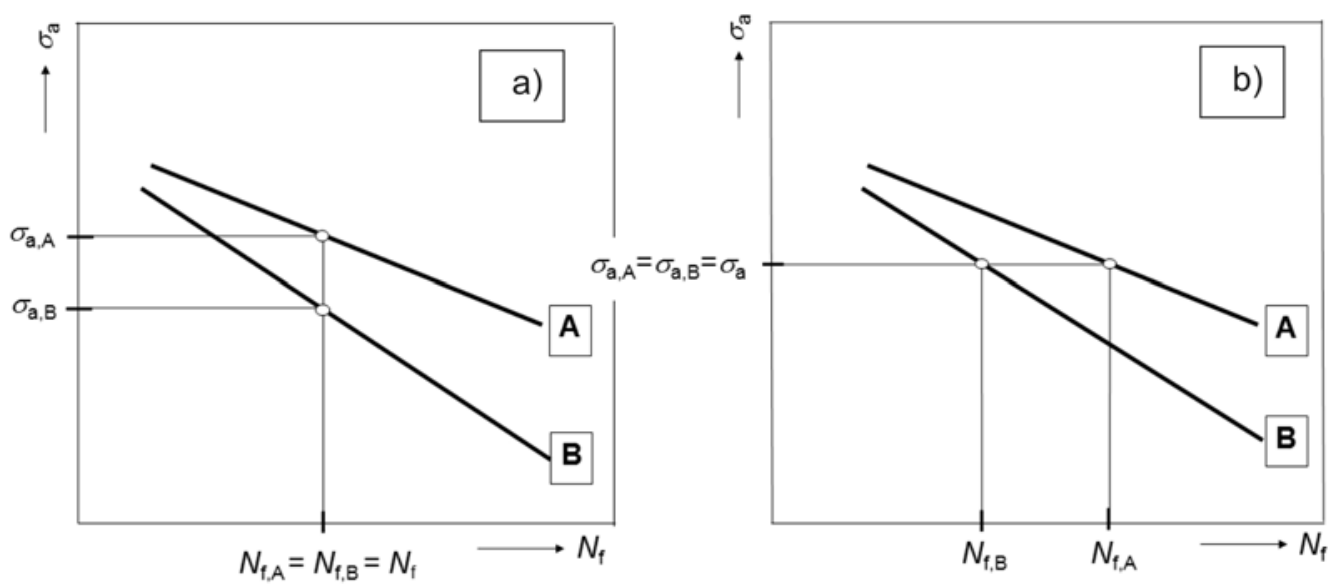

Fig. 7. Notch effect of the weld: a) - Eq. (2); b) - Eq. (4).

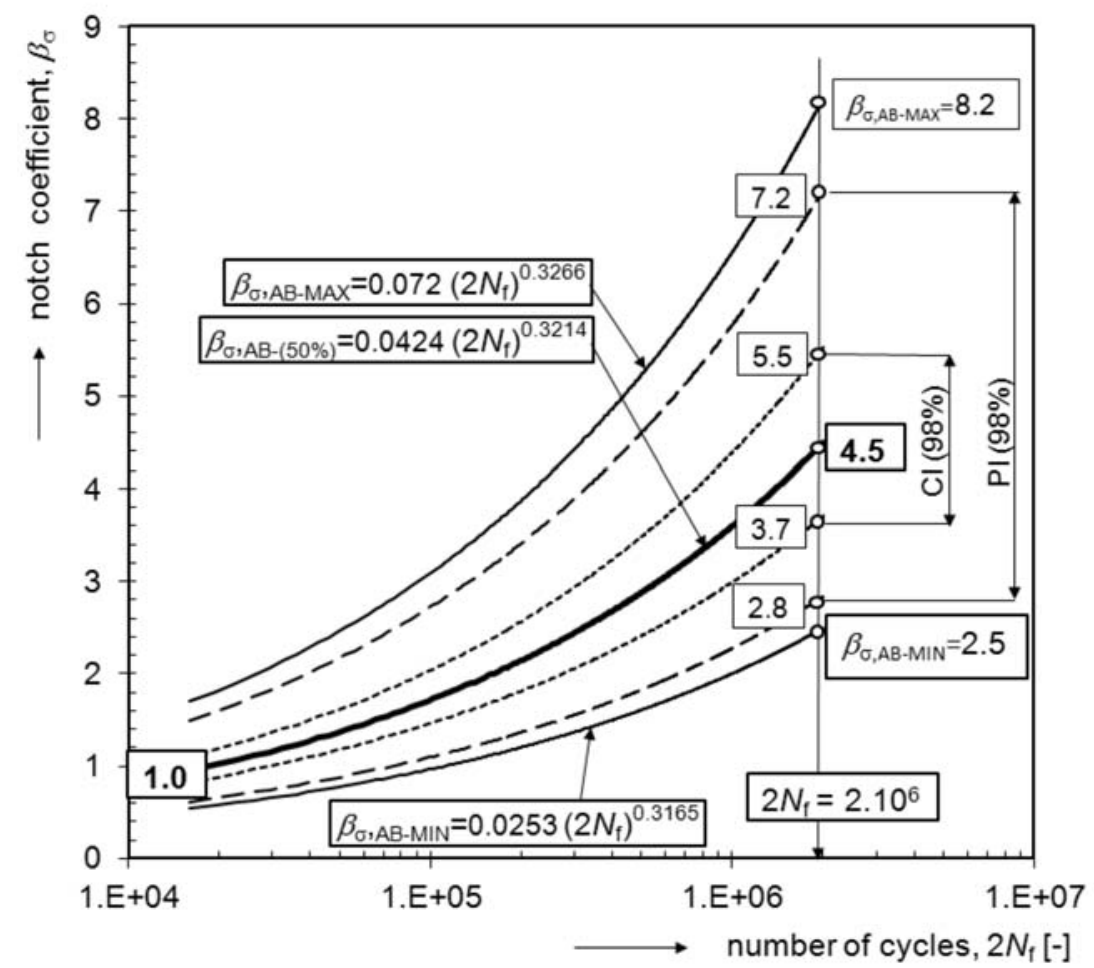

Fig. 8. Probabilistic interpretation of the notch coefficient $\beta_{\sigma, \mathrm{AB}}=f\left(N_{\mathrm{f}}\right) . C I(98 \%) / P I(98 \%)-98 \%$ confidence/prediction interval of the notch coefficient $\beta_{\sigma, \mathrm{AB}} ; \beta_{\sigma, \mathrm{AB}}^{\mathrm{MAX}(\mathrm{MIN})}-\operatorname{maximum}(\operatorname{minimum})$ value of the notch coefficient $\beta_{\sigma, \mathrm{AB}}$ for $P I(98 \%)$, Eq. (6).

main of the fatigue strength (Fig. 7a) by the relation

$$
\beta_{\sigma, \mathrm{AB}}=\frac{\sigma_{\mathrm{a}, \mathrm{A}}}{\sigma_{\mathrm{a}, \mathrm{B}}} .
$$

Alternatively, by considering Eq. (1) for the given number of cycles $N_{\mathrm{f}, \mathrm{A}}=N_{\mathrm{f}, \mathrm{B}}=N_{\mathrm{f}}$

$$
\beta_{\sigma, \mathrm{AB}}=\frac{\sigma_{\mathrm{f}^{\prime}, \mathrm{A}}}{\sigma_{\mathrm{f}^{\prime}, \mathrm{B}}}\left(2 N_{\mathrm{f}}\right)^{b_{\mathrm{A}}-b_{\mathrm{B}}} .
$$

Analogously, we can express the notch coefficient in this domain as a function of the stress (Fig. 7b) by the relation

$$
\beta_{\mathrm{N}, \mathrm{AB}}=\frac{N_{\mathrm{f}, \mathrm{A}}}{N_{\mathrm{f}, \mathrm{B}}}=\frac{\left(\sigma_{\mathrm{f}^{\prime}, \mathrm{B}}\right)^{\frac{1}{b_{\mathrm{B}}}}}{\left(\sigma_{\mathrm{f}^{\prime}, \mathrm{A}}\right)^{\frac{1}{b_{\mathrm{A}}}}} \sigma_{\mathrm{a}}^{\left(\frac{1}{b_{\mathrm{A}}}-\frac{1}{b_{\mathrm{B}}}\right)},
$$

where $\sigma_{\mathrm{f}^{\prime}}, b$ are parameters of Eq. (1) for the fatigue life curves $\mathbf{A}$ and $\mathbf{B}$ in Fig. 5. 
From the comparison of fatigue life curves $\mathbf{A}$ and B (represented by regression curves) in Fig. 5, it can be stated that:

- the notch effect in the time domain of the fatigue strength is a function of the number of cycles $N_{\mathrm{f}}$ and

- the value of notch coefficient $\beta_{\sigma, \mathrm{AB}}$ grows significantly with increasing number of cycles $N_{\mathrm{f}}$ (in compliance with Eq. (3)).

The course of the curve $\beta_{\sigma, \mathrm{AB}}=f\left(N_{\mathrm{f}}\right)$ is in Fig. 8 .

\subsubsection{The influence of the scatter of experimental points on value $\beta_{\sigma}$}

From Fig. 8 it can be seen that the notch coefficient $\beta_{\sigma, \mathrm{AB}}$ for $50 \%$ probability of occurrence (i.e., based on Eq. (3) for parameters of Eq. (1) represented by regression curves $\mathbf{A}$ and $\mathbf{B})$ reaches in the observed domain $2 N_{\mathrm{f}} \in\left(2 \times 10^{4} ; 2 \times 10^{6}\right)$ the values from 1.0 up to 4.5 . When we consider the scattering bands of curves $\mathbf{A}$ and $\mathbf{B}$ (represented by the $98 \% C I$ ) then the coefficient $\beta_{\sigma, \mathrm{AB}}$ will, for each number of cycles $N_{\mathrm{f}}$, obtain values within the frame of the corresponding scattering band, e.g. for $2 N_{\mathrm{f}}=2 \times 10^{6}$ we can expect with $98 \%$ probability the occurrence of the value $\beta_{\sigma, \mathrm{AB}}$ in the interval (3.7-5.5).

However, when we assess the operational reliability, the scatter band represented by $P I$ is more important, and it can be seen in Fig. 5 that a $98 \% P I$ on curve $\mathbf{B}$ is much larger than the one on curve $\mathbf{A}$. This gives evidence of a large number of factors influencing the fatigue life of the welded joint and causing a large scatter of the value $\beta_{\sigma, \mathrm{AB}}$ which for $98 \% P I$ and $2 N_{\mathrm{f}}=2 \times 10^{6}$ cycles can reach values in the interval (2.8-7.2), Fig. 8.

Let us note that in Fig. 8 we can see the courses $\beta_{\sigma, \mathrm{AB}}=f\left(N_{\mathrm{f}}\right)$ for the case when Eq. (2) has the form

$$
\beta_{\sigma, \mathrm{AB}}=\frac{\sigma_{\mathrm{a}, \mathrm{A}}^{(P \%)}}{\sigma_{\mathrm{a}, \mathrm{B}}^{(P \%)}},
$$

i.e. in determining the value $\beta_{\sigma, \mathrm{AB}}$ we consider that the curves $\mathbf{A}$ and $\mathbf{B}$ have the same probability of occurrence $P \%$. In reality, the fatigue life curves $\mathbf{A}$ and $\mathbf{B}$ can be applied in Eq. (5) with different values of $P \%$. For example, a case can occur where the basic material (curve A, Fig. 5) is represented by a point $\mathrm{A}(99 \%)$ and the welded joint (curve $\mathbf{B}$ ) by a point $\mathrm{B}(1 \%)$. In such a case, the coefficient value $\beta_{\sigma, \mathrm{AB}}$ is maximal, and for $2 N_{\mathrm{f} 1}=2 \times 10^{6}$ cycles and $P I(98 \%)$

$$
\beta_{\sigma, \mathrm{AB}}^{\mathrm{MAX}}=\frac{\sigma_{\mathrm{a}, \mathrm{A}}^{(99 \%)}}{\sigma_{\mathrm{a}, \mathrm{B}}^{(1 \%)}}=8.22 .
$$

However, for the same number of cycles $N_{\mathrm{f} 1}$ (Fig. 5), the opposite situation can occur as well, where $\beta_{\sigma, \mathrm{AB}}$ obtains the minimal value, i.e.

$$
\beta_{\sigma, \mathrm{AB}}^{\mathrm{MIN}}=\frac{\sigma_{\mathrm{a}, \mathrm{A}}^{(1 \%)}}{\sigma_{\mathrm{a}, \mathrm{B}}^{(99 \%)}}=2.49 .
$$

In fact, in determining $\beta_{\sigma, \mathrm{AB}}$, any random combination of values $P \%$ between the curves $\mathbf{A}$ and $\mathbf{B}$ can occur. The behavior of $\beta_{\sigma, \mathrm{AB}}^{\mathrm{MIN}}$ and $\beta_{\sigma, \mathrm{AB}}^{\mathrm{MAX}}$ as functions of the number of cycles $N_{\mathrm{f}}$ is presented in Fig. 8.

Thus, the notch coefficient of the weld can, with regard to the material scatter, take values in a wide range (for $2 N_{\mathrm{f} 1}=2 \times 10^{6}$ cycles in the interval from 2.5 to 8.2 , Fig. 8 ) and for the assessment of the risk of fatigue fracture in the welded joint the probability character of the $\beta_{\sigma, \mathrm{AB}}$ should be considered. The value $\beta_{\sigma, \mathrm{AB}}^{(P \%)}$, for the required probability of occurrence $P \%$, can be determined (for a given cycles number $N_{\mathrm{f}}$ ) from the distribution function (DF) of the coefficient $\beta_{\sigma, \mathrm{AB}}$. The set of values $\beta_{\sigma, \mathrm{AB}}$, necessary for the $\mathrm{DF}$ computation, can be obtained using Eq. (5) for all combinations $P \%$ of the curves $\mathbf{A}$ and $\mathbf{B}$. The DF of the notch coefficient $\beta_{\sigma, \mathrm{AB}}$ for $2 N_{\mathrm{f}}=2 \times 10^{6}$ cycles is presented in Fig. 9.

\subsubsection{Notch effect in the low cycle domain}

The trend $\beta_{\sigma, \mathrm{AB}}=f\left(N_{\mathrm{f}}\right)$ in the high cycle domain (i.e., when $N_{\mathrm{f}}$ decreases, the value $\beta_{\sigma, \mathrm{AB}}$ decreases as well, Fig. 8) continues also in the low cycle domain until the value $2 N_{\mathrm{f}} \approx 2 \times 10^{4}$ cycles, where the regression curve $\mathbf{B}$ is crossed with curve $\mathbf{A}$, (Fig. 5), i.e. $\beta_{\sigma, \mathrm{AB}}=1$. If we extrapolate the curve $\mathbf{B}$ further into the domain $2 N_{\mathrm{f}}<2 \times 10^{4}$, then the welded joint would show better fatigue properties than the basic material represented by curve $\mathbf{A}$. In such a case the IIW recommends [4] that, in the life calculations for this domain, the curve of the basic material $\mathbf{A}$ be considered instead of the fatigue life curve of the welded joint $\mathbf{B}$.

It should be noted that in our case there is no experimental point at our disposal which would justify simply lengthening the curve $\mathbf{B}$ into this area. Therefore a more credible idea is that, concerning the high level of stress and the loading regime with $\sigma_{\mathrm{a}}=$ const, we already are in an area with another damaging mechanism. The change in this mechanism under the loading regime $\sigma_{\mathrm{a}}=$ const can lead to the disintegration of the fatigue life curve and the creation of discontinuous behavior. In spite of the insufficient number of experimental points, it is possible to observe this trend in curve B. A discontinually evaluated course of curve $\mathbf{B}$ (from an insufficient number of points) is presented in Fig. 10. Curve $\mathbf{B}$ disintegrates into parts $\mathbf{B} 1$ and $\mathbf{B} 2$ with discontinuity $(d)$ at the loading level $\sigma_{\mathrm{a}} \approx 230 \mathrm{MPa}$, which approximately corresponds to the dividing line between the low and 


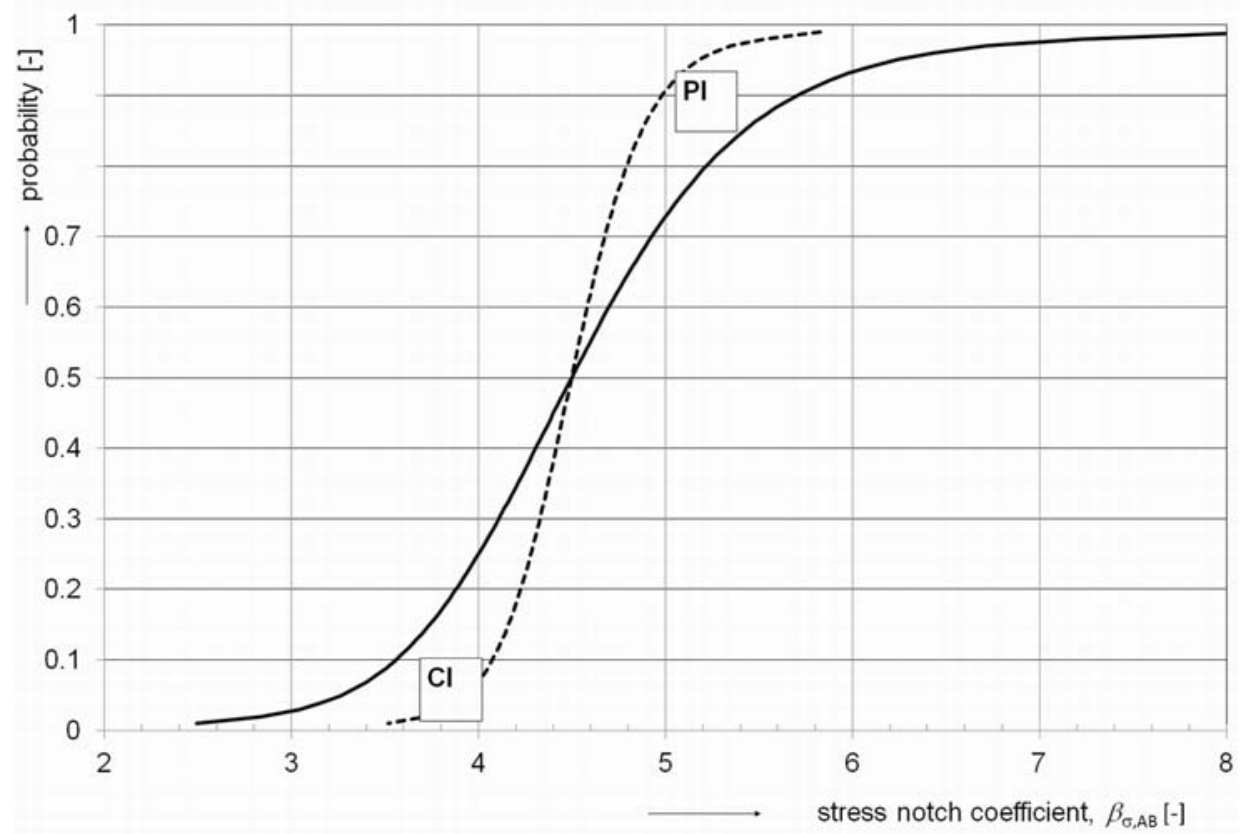

Fig. 9. Distribution function $(D F)$ of the weld notch coefficient $\beta_{\sigma, \mathrm{AB}}$ for $2 N_{\mathrm{f}}=2 \times 10^{6}$ cycles. $C I-D F$ of the total notch coefficient $\beta_{\sigma, \mathrm{AB}}$ considering the scatter of regression lines $\mathbf{A}$ and $\mathbf{B} ; P I-D F$ of the total notch coefficient $\beta_{\sigma, \mathrm{AB}}$ regarding the scatter of experimental points around the fatigue life curves $\mathbf{A}$ and $\mathbf{B}$.

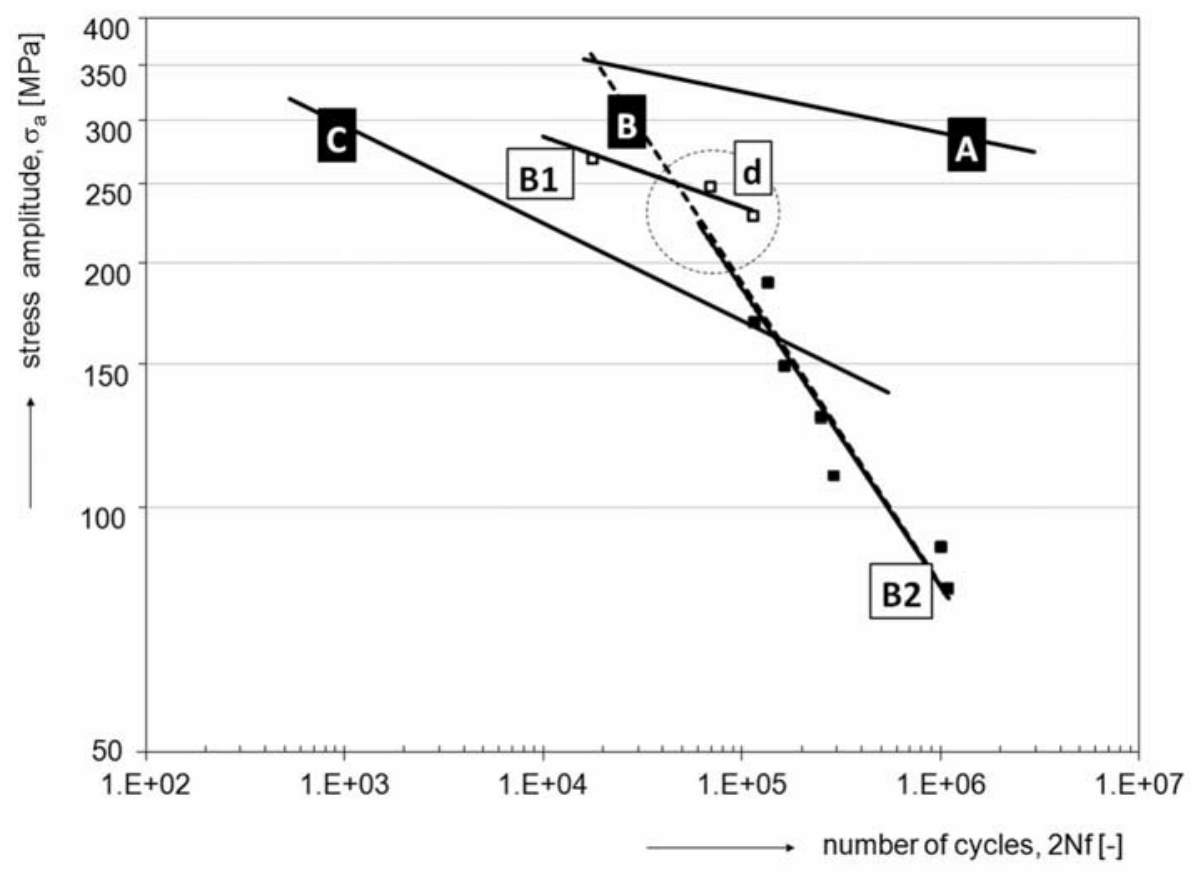

Fig. 10. Discontinuity in the behavior of the fatigue life curve of welded joint: $\mathbf{A}$ - basic material; B - welded joint; B1, B2 - welded joint with discontinuity $(d) ; \mathbf{C}-$ ground welded joint.

high cycle fatigue. In the area of high cycle fatigue, the curves $\mathbf{B}$ and $\mathbf{B 2}$ are practically identical. In such a case, in the areas of higher loadings, it is more realistic to consider curve $\mathbf{B} \mathbf{1}$ instead of curve $\mathbf{A}$ in the fatigue life calculations.

\subsection{Effect of weld grinding}

The effect of weld grinding can be judged from the behavior and comparison of fatigue life curve $\mathbf{C}$ with curves $\mathbf{A}$ and $\mathbf{B}$ (Fig. 5). By grinding the weld, the 


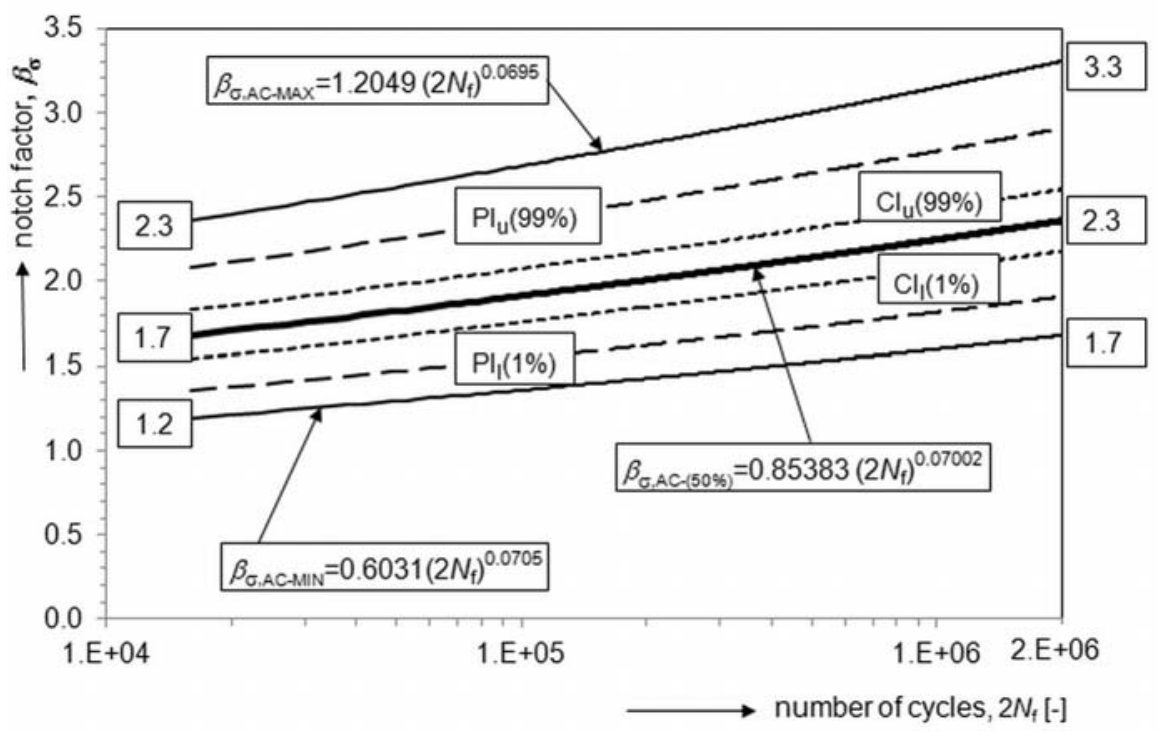

Fig. 11. Probabilistic interpretation of the technological notch coefficient $\beta_{\sigma, \mathrm{AC}}=f\left(2 N_{\mathrm{f}}\right)$. $P I_{1}\left(P I_{\mathrm{u}}\right)-$ lower (upper) tolerance limit for $98 \%$ prediction interval; $C I_{1}\left(C I_{\mathrm{u}}\right)$ - lower (upper) tolerance limit for $98 \%$ confidence interval; $\beta_{\sigma, \mathrm{AC}}^{\mathrm{MAX}(\mathrm{MIN})}$ - maximum (minimum) value of the notch coefficient $\beta_{\sigma, \mathrm{AC}}$ for $P I(98 \%)$.

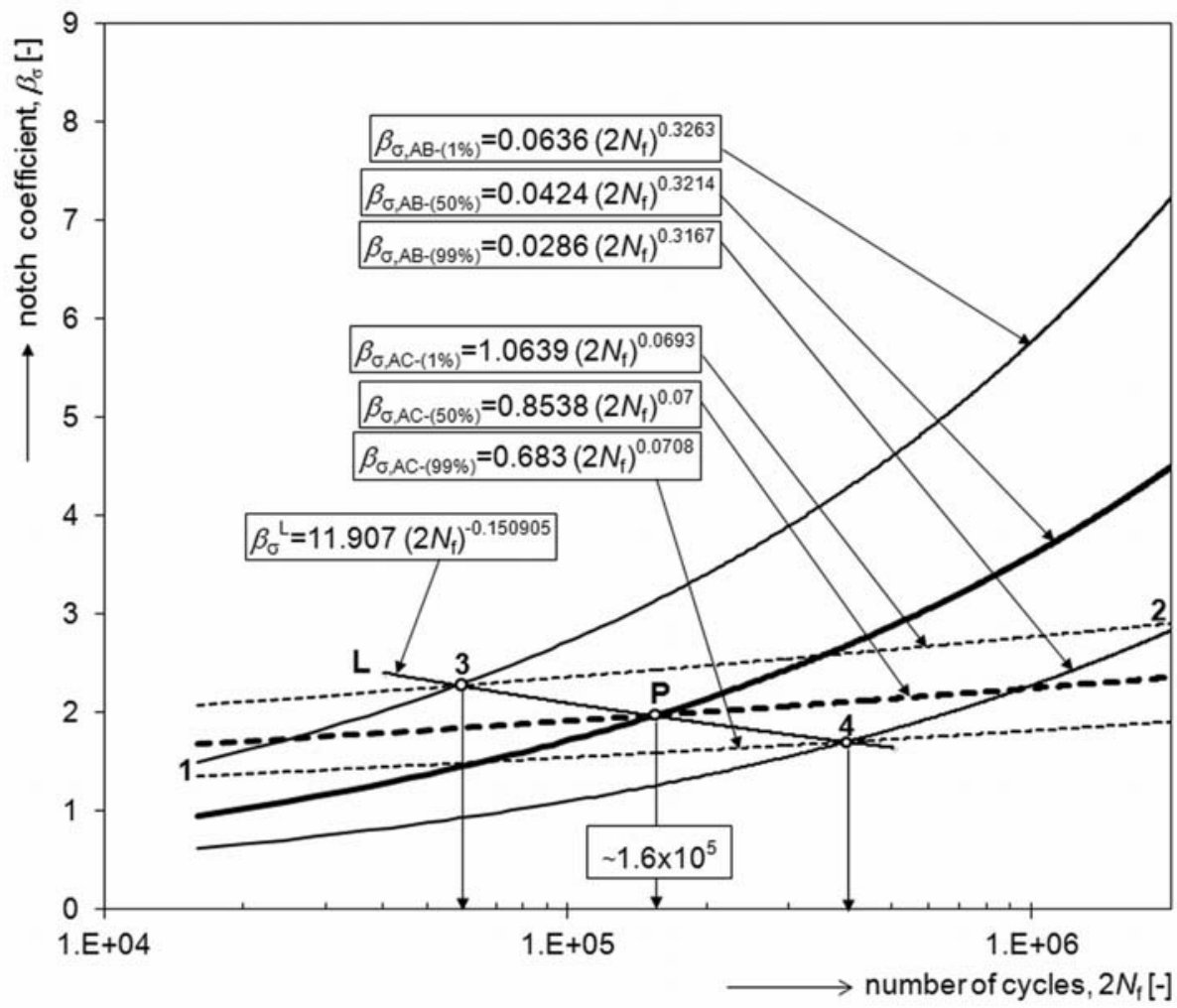

Fig. 12. Comparison of the notch coefficients of the welded joint $\beta_{\sigma, \mathrm{AB}}$ and $\beta_{\sigma, \mathrm{AC}}$ together with $98 \%$ prediction intervals. $\beta_{\sigma, \mathrm{AB}}$ - course of the total weld notch coefficient; $\beta_{\sigma, \mathrm{AC}}$ - course of the technological weld notch coefficient (ground weld); $\beta_{\sigma, \mathrm{AB}-(1 \%)}$ - course of the total notch coefficient for $1 \%$ probability of occurrence (lower tolerance limit of the PI $(98 \%)$ ); $\mathbf{L}$ - demarcation line dividing the grinding effect into positive and negative outcomes.

geometrical concentrator of stress was removed, and curve $\mathbf{C}$ then represents only the influence of technological factors (Fig. 1). Their notch effect is represen- ted by the behavior of the notch coefficient $\beta_{\sigma, \mathrm{AC}}$ in Fig. 11. By comparing the curves $\mathbf{C}$ and $\mathbf{A}$ in Fig. 5 as well as from the behavior of $\beta_{\sigma, \mathrm{AC}}$ in Fig. 11, it 
can be seen that the change of $\beta_{\sigma, \mathrm{AC}}$ with number of cycles $N_{\mathrm{f}}$ is not so distinctive as in the case of the coefficient $\beta_{\sigma, \mathrm{AB}}$ (Fig. 8). In the observed life interval, the $\beta_{\sigma, \mathrm{AC}}$ obtains values from 1.7 to 2.3 (for parameters of the regression curves $\mathbf{C}$ and $\mathbf{A}$ ), Fig. 11. However, with regard to the scatter of experimental results, the value of $\beta_{\sigma, \mathrm{AC}}$ can be in a wider interval, e.g., for $2 N_{\mathrm{f}}$ $=2 \times 10^{6}$ cycles we can expect a value $\beta_{\sigma, \mathrm{AC}}$ in the interval (1.7-3.3). The comparison of the notch coefficients $\beta_{\sigma, \mathrm{AB}}$ and $\beta_{\sigma, \mathrm{AC}}$ is in Fig. 12. The borders of the scatter bands of the curves $\beta_{\sigma, \mathrm{AB}}=f\left(2 N_{\mathrm{f}}\right)$ and $\beta_{\sigma, \mathrm{AC}}=f\left(2 N_{\mathrm{f}}\right)$ are calculated using Eq. (5) for $P I(98 \%)$.

\subsubsection{The influence of the scatter of experimental points on the weld grinding effect}

From Figs. 5 and 12 it can be seen that the point of intersection $(\mathbf{P})$ of the curves $\mathbf{B}$ and $\mathbf{C}$ divides the fatigue life into an area where the grinding effect of the weld is positive $\left(\beta_{\sigma, \mathrm{AC}}<\beta_{\sigma, \mathrm{AB}}\right.$, Fig. 12) and an area where the grinding effect is negative $\left(\beta_{\sigma, \mathrm{AC}}>\beta_{\sigma, \mathrm{AB}}\right)$. For the $50 \%$ fatigue life curves, the dividing value is $2 N_{\mathrm{f}} \approx 1.6 \times 10^{5}$ cycles at $\sigma_{\mathrm{a}} \approx 160 \mathrm{MPa}$, Fig. 5 . However, regarding the scatter of experimental points around the fatigue life curves $\mathbf{B}$ and $\mathbf{C}$, as well as intersection of their scatter bands, it is not possible to unambiguously determine whether the effect of grinding is negative with loading $\sigma_{\mathrm{a}}>160 \mathrm{MPa}$, or on the contrary, positive with loading $\sigma_{\mathrm{a}}<160 \mathrm{MPa}$. The reason for this is the large common scatter band of curves $\mathbf{B}$ and $\mathbf{C}$ (area bounded by points 1-3-2-4-1, Fig. 5) in which most of experimental results of the fatigue life for curves $\mathbf{B}$ and $\mathbf{C}$ occur. What we can say with certainty is that for load amplitude $\sigma_{\mathrm{a}} \geq \sigma_{\mathrm{a} 1}$ (Fig. 5) the effect of grinding will always be negative and for load amplitude $\sigma_{\mathrm{a}} \leq \sigma_{\mathrm{a} 2}$ (Fig. 5) is always positive. Under loading with $\sigma_{\mathrm{a}} \in\left\langle\sigma_{\mathrm{a} 1} ; \sigma_{\mathrm{a} 2}\right\rangle$ we can speak only about the value of probability of the positive or negative effect of the weld grinding, depending on the probability of occurrence of an unground weld. For instance, if under loading with $\sigma_{\mathrm{a}}=\sigma_{\mathrm{a} 3}$ (Fig. 5) the fatigue life of the unground weld was $2 N_{\mathrm{f} 3}$, then with $99 \%$ probability the effect of weld grinding would be positive and with $1 \%$ probability it would be negative. The smaller the scatter bands around the fatigue life curves, the smaller is an interval $\left\langle\sigma_{\mathrm{a} 1} ; \sigma_{\mathrm{a} 2}\right\rangle$ and the more unambiguously it is possible to judge the efficiency of the weld grinding. In general, the point $\mathbf{P}$, which divides the grinding effect into positive and negative outcomes, is a function of the probability of the occurrence (demarcation line $\mathbf{L}$ in Fig. 12).

Experimentally obtained values $\sigma_{\mathrm{a} 1}$ and $\sigma_{\mathrm{a} 2}$ (for the given type of weld) are even more important under the random operational loading. In such a case, in order to judge the effect of the weld grinding, we would have to take into consideration the distribution of the loading process (probability density function) and relate it to the obtained values of $\sigma_{\mathrm{a} 1}$ and $\sigma_{\mathrm{a} 2}$.

\subsubsection{The influence of the geometrical factors on the notch effect of the weld}

The influence of geometrical factors (Fig. 1) on fatigue life of the welded joint is represented by the geometrical notch coefficient $\beta_{\sigma, G}$, which is defined by the following relation

$$
\beta_{\sigma, \mathrm{G}}=\frac{\sigma_{\mathrm{a}, \mathrm{A}}}{\sigma_{\mathrm{a}, \mathrm{G}}}
$$

Virtual fatigue life curve G (Fig. 13), needed for calculation of $\beta_{\sigma, \mathrm{G}}$ according to Eq. (8), can be determined through the use of experimentally obtained curves $\mathbf{A}, \mathbf{B}$ and $\mathbf{C}$ (Fig. 5).

The following relation is valid for the $2 N_{\mathrm{f} 1}$ number of cycles (Fig. 13)

$$
\left(\sigma_{\mathrm{a}, \mathrm{A}}-\sigma_{\mathrm{a}, \mathrm{B}}\right)=\left(\sigma_{\mathrm{a}, \mathrm{A}}-\sigma_{\mathrm{a}, \mathrm{C}}\right)+\left(\sigma_{\mathrm{a}, \mathrm{C}}-\sigma_{\mathrm{a}, \mathrm{B}}\right),
$$

where $\left(\sigma_{\mathrm{a}, \mathrm{A}}-\sigma_{\mathrm{a}, \mathrm{C}}\right)$ is the change of $\sigma_{\mathrm{a}}$ as a result of the influence of the technological factors (Fig. 1), which are represented by the technological notch coefficient

$$
\beta_{\sigma, \mathrm{AC}}=\frac{\sigma_{\mathrm{a}, \mathrm{A}}}{\sigma_{\mathrm{a}, \mathrm{C}}}=\beta_{\sigma, \mathrm{T}},
$$

$\left(\sigma_{\mathrm{a}, \mathrm{C}}-\sigma_{\mathrm{a}, \mathrm{B}}\right)$ is the change of $\sigma_{\mathrm{a}}$, which represents the influence of the geometrical factors (Fig. 1), i.e.

$$
\left(\sigma_{\mathrm{a}, \mathrm{C}}-\sigma_{\mathrm{a}, \mathrm{B}}\right)=\left(\sigma_{\mathrm{a}, \mathrm{A}}-\sigma_{\mathrm{a}, \mathrm{G}}\right) .
$$

Through the combination of Eqs. (9) and (11) the sought value of $\sigma_{\mathrm{a}, \mathrm{G}}$ on the virtual fatigue life curve G (Fig. 13) is

$$
\sigma_{\mathrm{a}, \mathrm{G}}=\sigma_{\mathrm{a}, \mathrm{A}}+\sigma_{\mathrm{a}, \mathrm{B}}-\sigma_{\mathrm{a}, \mathrm{C}} .
$$

Then, with respect to Eqs. (2), (10) and (12), the relation for the geometrical notch coefficient defined by Eq. (8) becomes

$$
\beta_{\sigma, \mathrm{G}}=\frac{\beta_{\sigma, \mathrm{AB}} \beta_{\sigma, \mathrm{T}}}{\beta_{\sigma, \mathrm{AB}} \beta_{\sigma, \mathrm{T}}+\beta_{\sigma, \mathrm{T}}-\beta_{\sigma, \mathrm{AB}}} .
$$

Relation for the total notch coefficient $\beta_{\sigma, \mathrm{AB}}$, as a function of $\beta_{\sigma, \mathrm{T}}$ and $\beta_{\sigma, \mathrm{G}}$, can be obtained in the form

$$
\beta_{\sigma, \mathrm{AB}}=\frac{\beta_{\sigma, \mathrm{T}} \beta_{\sigma, \mathrm{G}}}{\beta_{\sigma, \mathrm{T}}+\beta_{\sigma, \mathrm{G}}-\beta_{\sigma, \mathrm{G}} \beta_{\sigma, \mathrm{T}}} .
$$




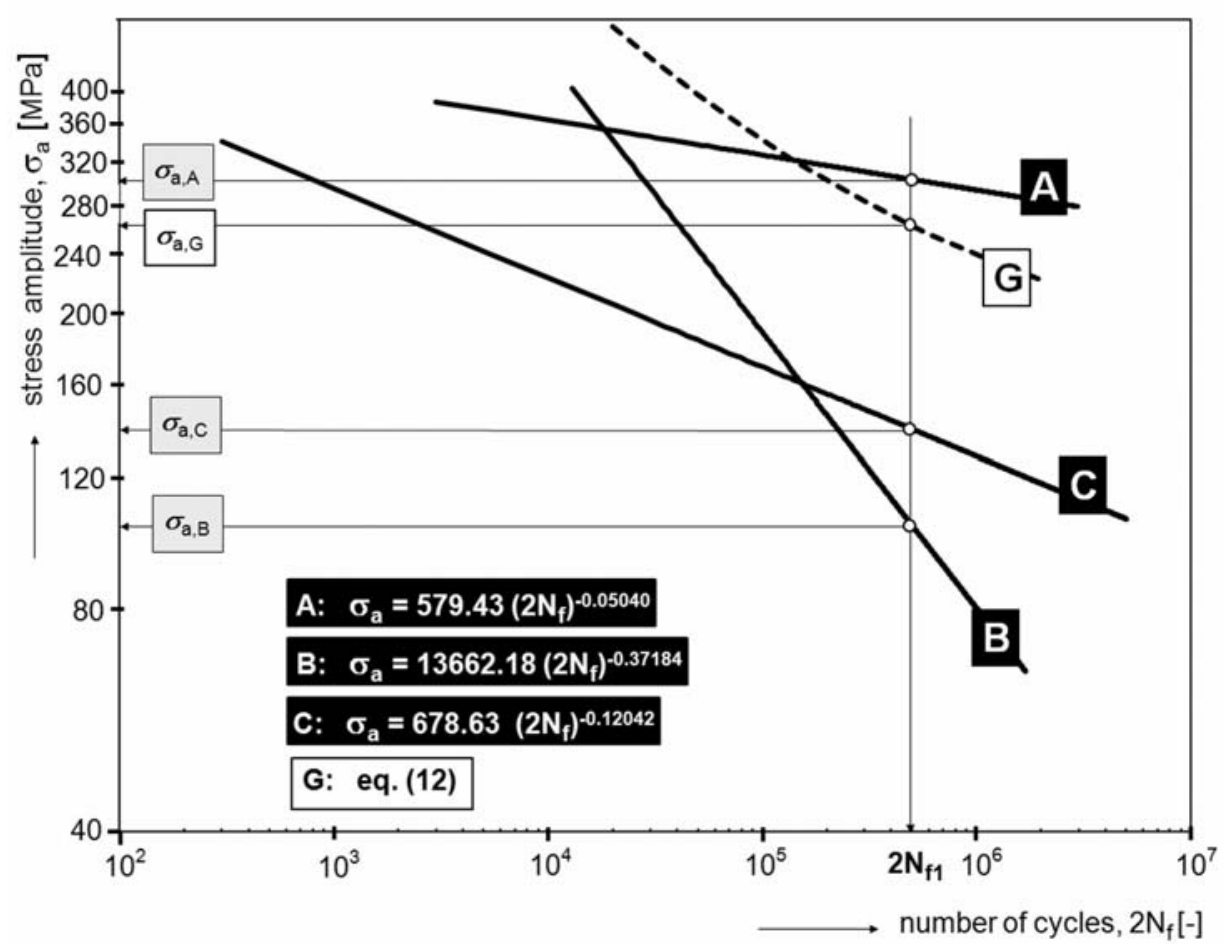

Fig. 13. Fatigue life curves. A - basic material; B - welded joint; $\mathbf{C}$ - ground welded joint; $\mathbf{G}$ - virtual fatigue life curve (Eq. (12)).

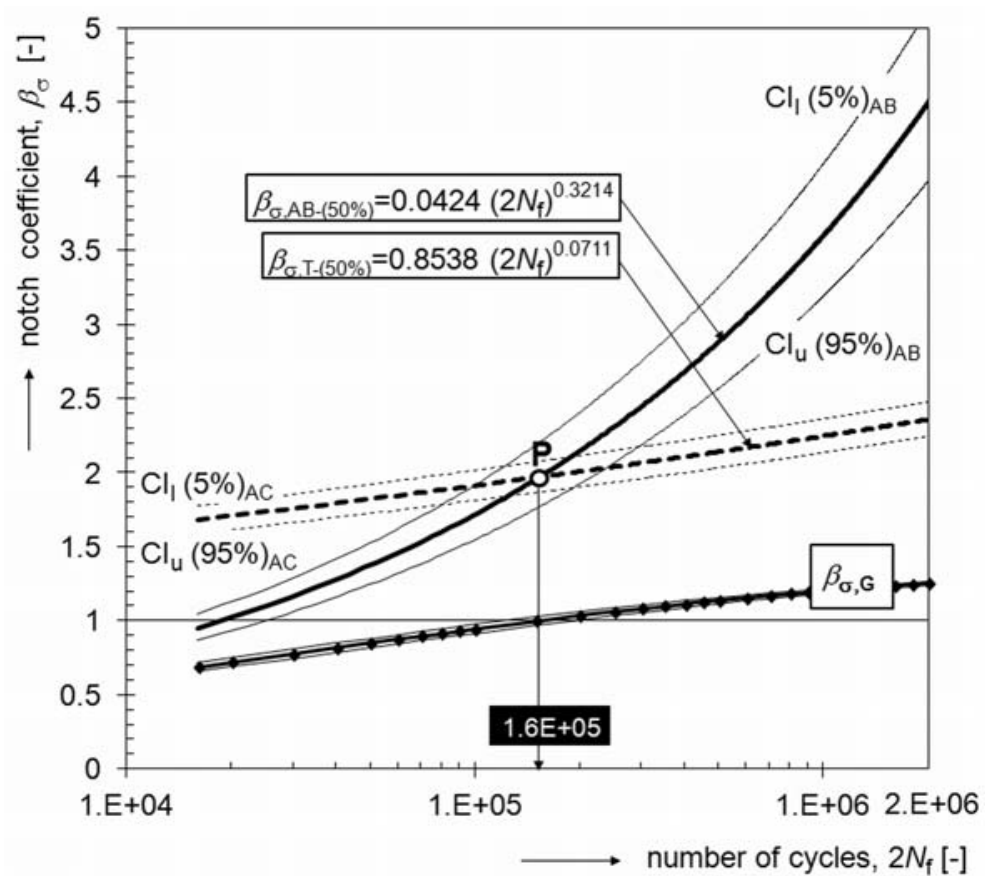

Fig. 14. Behavior of the notch coefficients of the welded joint. $\beta_{\sigma, \mathrm{AB}}-$ total weld notch coefficient; $\beta_{\sigma, \mathrm{AC}}=\beta_{\sigma, \mathrm{T}}-$ technological weld notch coefficient (ground weld); $\beta_{\sigma, \mathrm{G}}-$ geometrical weld notch coefficient (Eq. (13)).

Equation (13) enables us to calculate, for a given number of cycles $2 N_{\mathrm{f}}$, the value of geometrical notch coefficient $\beta_{\sigma, \mathrm{G}}$ using already known values of coefficients $\beta_{\sigma, \mathrm{AB}}$ and $\beta_{\sigma, \mathrm{T}}$. The course of the notch coef- ficients $\beta_{\sigma, \mathrm{AB}}, \beta_{\sigma, \mathrm{AC}}=\beta_{\sigma, \mathrm{T}}$ and $\beta_{\sigma, \mathrm{G}}(\mathrm{Eq} .(13))$, together with the scatter bands calculated for $90 \%$ confidence interval of fatigue life curves A, B and $\mathbf{C}$, can be seen in Fig. 14. 
From Figs. 13 and 14 it can be seen that in the given case of welded joint:

- the geometrical notch coefficient $\beta_{\sigma, \mathrm{G}}$ obtains values less than $\mathbf{1}$ in the low-cycle domain and greater than 1 in the high-cycle domain,

- the values of technological notch coefficient $\beta_{\sigma, \mathrm{T}}$ are greater than $\mathbf{1}$ along the whole observed life domain and are approximately two times larger than the values of $\beta_{\sigma, \mathrm{G}}$,

- the technological notch coefficient $\beta_{\sigma, \mathrm{T}}$ has a decisive influence on fatigue life of the weld over the whole observed life domain, and the geometrical factors (Fig. 1) only increase (in high cycle domain) or decrease (in low cycle domain) the notch effect of so-called technological factors.

For the behavior of the ground welded joint, the following explanation can be then offered:

- At high amplitudes of loading, i.e. in the low cycle fatigue, the plastic deformation can occur in the weld toe which results in the lowering of the stress concentrator, material hardening and the creation of residual pressure stresses. These are the factors that positively influence the fatigue life of plastically deformed notched parts [11], and the geometrical factors in such a case act against (the value of $\beta_{\sigma, \mathrm{G}}<1$ ) the negative effect of the technological factors. The result is that in the domain of high loading levels (in accordance with Eq. (14)) the total notch coefficient of the weld $\beta_{\sigma, \mathrm{AB}}<\beta_{\sigma, \mathrm{T}}$, i.e. the fatigue life of specimens with ground welds is shorter than the fatigue life of specimens with unground welds, Fig. 5.

- In the high cycle domain, the geometrical concentrator can significantly increase the stress in the weld toe compared with the nominal one, what has a dominant influence on the initiation of a fatigue crack. The geometrical factors, in this case, contribute $\left(\beta_{\sigma, G}>1\right)$ to the negative effect of the technological factors and, by Eq. (14), in this domain the total notch coefficient $\beta_{\sigma, \mathrm{AB}}>\beta_{\sigma, \mathrm{T}}$. It means that in this region the fatigue life of specimens with ground welds is larger than the fatigue life of specimens with unground welds (Fig. 5).

- Removal of the geometrical stress concentrator in the weld toe by weld grinding can be effective especially for the low loading levels, i.e. in the high cycle domain and in the region of so-called permanent fatigue strength. This conclusion is confirmed also by the fact that in the high cycle domain the fatigue crack was initiated exclusively in the weld toe (Fig. 15b), while in the domain of higher loading levels, it was mostly caused by inner defects (Fig. 15a). Inner defects found in the weld of the tested specimen, as well as changes in the structure in the result of thermal processes within the welding cycle, can be seen in Fig. 16a, $\mathrm{b}, \mathrm{c}$.

- In the region of $\sigma_{\mathrm{a}} \in\left\langle\sigma_{\mathrm{a} 1} ; \sigma_{\mathrm{a} 2}\right\rangle$, Fig. 5, the effect of weld grinding has a probabilistic character (section 3.2 .1 )
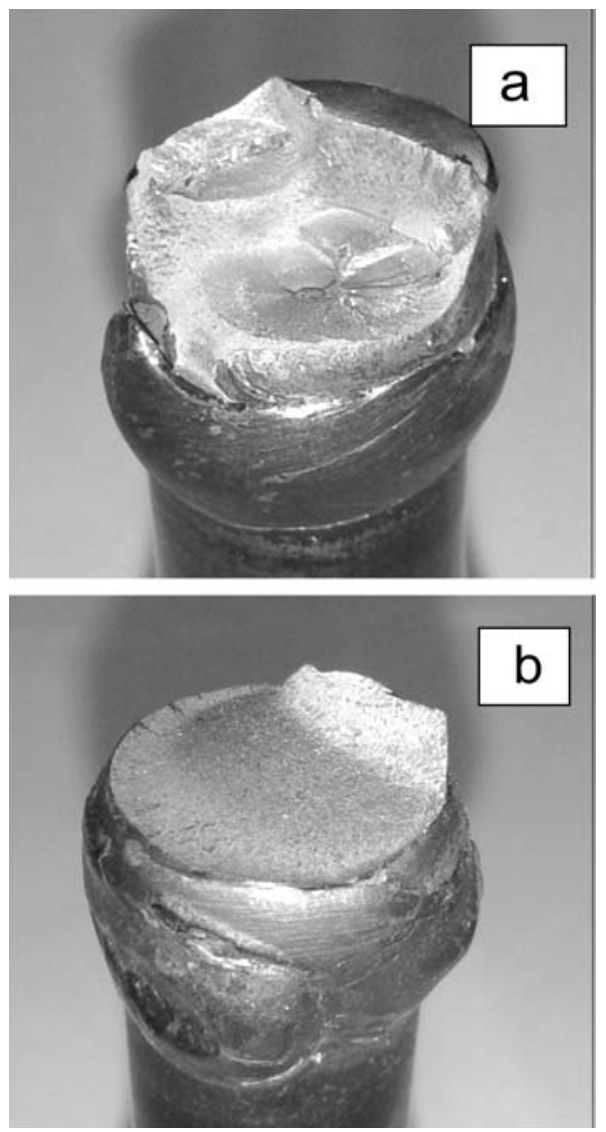

Fig. 15. Initiation and propagation of fatigue crack. a) from the inner defect; b) - from the weld toe.

\section{Conclusions}

1. Concerning the material scatter, the values of the notch coefficient $\beta_{\sigma}$ can be found in a wide range. Therefore, when assessing the risk of a fracture occurrence in the welded joint, it is necessary to consider the probability character of the $\beta_{\sigma, \mathrm{AB}}$. The value of $\beta_{\sigma, \mathrm{AB}}$ for the desired probability of occurrence can be determined from the distribution function of the coefficient $\beta_{\sigma, \mathrm{AB}}$.

2. The technological notch coefficient $\beta_{\sigma, \mathrm{T}}$ has a decisive influence on fatigue life of the weld over the whole observed life domain, and the geometrical factors only increase (in high cycle domain) or decrease (in low cycle domain) the negative effect of technological factors.

3. Removal of the geometrical stress concentrator in the weld toe by weld grinding is highly effective for low loading levels (high cycle domain and the region of so-called permanent fatigue strength).

4. The effect of weld grinding is of a probabilistic character and depends on the size of the scatter of the experimental results around the fatigue life curves. When considering $P I(98 \%)$, the effect of grinding is positive under loading with the amplitude $\sigma_{\mathrm{a}} \leq \sigma_{\mathrm{a} 2}$ 

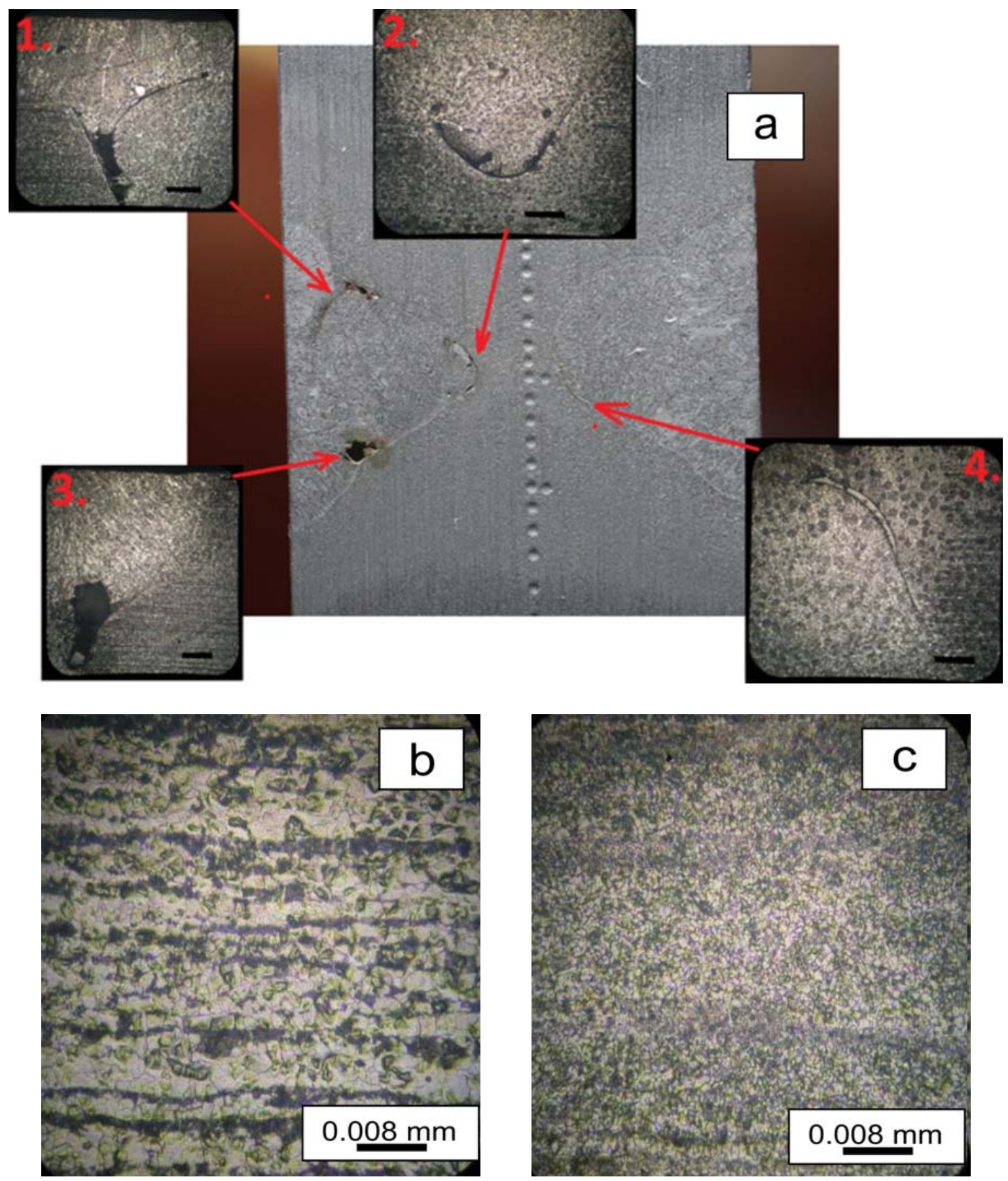

Fig. 16. Defects in the welded joint of the tested specimen and changes of the structure as a result of thermal processes within welding cycle. a) 1 - incomplete fusion; 2 - lack of penetration; 3 - bubble; 4 - inclusion, b) structure of the basic material - rolled steel bar, c) structure of the heat-affected zone.

and negative under loading with $\sigma_{\mathrm{a}} \geq \sigma_{\mathrm{a} 1}$ (Fig. 5). Under loading with $\sigma_{\mathrm{a}} \in\left\langle\sigma_{\mathrm{a} 1} ; \sigma_{\mathrm{a} 2}\right\rangle$, we can speak only about the probability of a positive or negative grinding effect.

5. It is always effective to simulate a real welded joint on the test specimens in the laboratory. We acquire in this way the material constants (needed for the fatigue damage calculation), which maximally relate to reality, and the possibility to assess the weld grinding effect for the given operational loading.

\section{Acknowledgements}

This work was financially supported by the Agency of the Ministry of Education, Science, Research and Sport of the Slovak Republic for the Structural Funds of EU under the contract of Operational Programme Research and 
Development: ITMS project code: 26240220081, project name: Industrial Research Centre for operating lifetime of selected components of power plants.

\section{References}

[1] Sonsino, C. M.: Frattura ed Integrità Strutturale, 9, 2009, p. 3. doi:10.3221/IGF-ESIS.09.01

[2] Radaj, D., Sonsino, C. M., Fricke, W.: Fatigue Assessment of Welded Joints by Local Approaches. 2nd Edition. Cambridge, Woodhead Publishing Ltd. 2006.

[3] Haagensen, P. J.: Fatigue Design of Welded Structures - Norsok and Eurocode 3. Trondheim, NTNU 2011.

[4] Hobbacher, A. (Ed.).: Recommendations for Fatigue Design of Welded Joints and Components. Document IIW-1823-07, ex XIII-2151r4-07/XV-1254r4-07. Paris, International Institute of Welding 2008.
[5] Hobbacher, A. F.: Int. J. Fatigue, 31, 2009, p. 50. doi:10.1016/j.ijfatigue.2008.04.002

[6] Eurocode 3. Design of Steel Structures. Part 1-9: Fatigue. UNI ENV 1993-1-9. Brussels, CEN 2015.

[7] Kliman, V., Kepka, M., Václavík, J.: Kovove Mater., 48, 2010, p. 367.

[8] Margetin, M.: Contribution to Fatigue Life Time Evaluation of Welded Joints. [Ph.D. thesis]. Bratislava, Slovak University of Technology in Bratislava 2012.

[9] Basquin, O. H.: Proceedings ASTM, 10, 1910, p. 625.

[10] Code of Practice for Fatigue Design and Assessment of Steel Structures. British Standard BS 7608. London, BSI 1993.

[11] Kliman, V., Bílý, M., Prochácka, J.: Int. J. Fatigue, 15, 1993, p. 93. doi:10.1016/0142-1123(93)90003-9 